\title{
Lower Urinary Tract Symptoms in Elderly Population With Multiple Sclerosis
}

\author{
Camille Chesnel $^{1,2, *}$, Audrey Charlanes ${ }^{1,2, *}$, Claire Hentzen ${ }^{1,2, *}$, Nicolas Turmel ${ }^{1,2, *}$, Frédérique Le Breton ${ }^{1,2}$, Samer Sheikh Ismael ${ }^{1,2}$, \\ Gérard Amarenco ${ }^{1,2, *}$; for the GRAPPPA (Groupe de Recherche Appliquée à la Pelvi-Périnéologie de la Personne Agée) ${ }^{\dagger}$ \\ ${ }^{1}$ GREEN GRC-01 UPMC (Group of clinical REsEarch in Neurouology), Sorbonne University, Paris, France \\ ${ }^{2}$ Department of Neuro-urology, Tenon Hospital, Paris, France
}

Purpose: The aim of this study is to compare the clinical and urodynamic characteristics of urinary disorders in multiple sclerosis (MS) patients in a geriatric population with a nongeriatric population.

Methods: This study was conducted retrospectively between 2010 and 2016. Each patient with MS aged 65 and older was matched with 2 patients with MS aged less than 65 in sex, form of MS, and Expended Disability Status Scale (EDSS). Demographic data, urinary symptoms, treatment, quality of life, repercussion of lower urinary tract symptoms on daily life activities and psychological state and urodynamic parameters were collected. Differences between the 2 populations were evaluated using Student test, chi-square, or Fischer tests.

Results: Twenty-four patients with MS aged 65 and older (mean age, 69.8 years) were matched with 48 patients aged less than 65 years (mean age, 49.4 years). Maximum urethral closure pressure was lower in the elderly population than in the nongeriatric population (mean \pm standard deviation [SD]: $35.6 \pm 18.5 \mathrm{~cm} \mathrm{H}_{2} \mathrm{O}$ vs. $78.2 \pm 52.3 \mathrm{~cm} \mathrm{H} \mathrm{H}_{2} \mathrm{O}, \mathrm{P}<0.001$ ). In the male population, there was no statistical difference in any other clinical or urodynamic endpoints. In the female population, voiding symptoms was more described in the nongeriatric population (Urinary Symptom Profile low stream: $3.4 \pm 3.5$ vs. $1.7 \pm 2.4, \mathrm{P}=0.04$ ), geriatric population had less urinary treatment $(\mathrm{P}=0.05)$. LUTS had less impact on quality of life (Qualiveen: $1.4 \pm 1.0 \mathrm{vs}$. $2.1 \pm 0.9, \mathrm{P}=0.02)$ on the geriatric population than in the nongeriatric of female MS patients.

Conclusions: Geriatric population of MS has few differences of urinary disorders compared to a nongeriatric population with EDSS, sex, and MS form equal. However, the psychological impact of these urinary disorders is less important in female geriatric population.

Keywords: Elderly; Lower urinary tract symptoms; Multiple sclerosis

- Research Ethics: This study was approved by a local ethics committee (Comité de Protection des Personnes Ile de France II: 00001072). Since it was retrospective and no formalized informed consent was necessary according to the ethics committee.

- Conflict of Interest: No potential conflict of interest relevant to this article was reported.

\section{INTRODUCTION}

Recent studies on multiple sclerosis (MS) showed longer survival times from clinical onset than older hospital-based series with a moderate overall excess mortality compared with the general population (standardized mortality ratio [SMR], 1.48; 95\% confidence interval [CI], 1.41-1.55]) [1]. Excess mortality increase after 20 years of disease (SMR, 2.20 [2.10-2.31]) [1]. In

Corresponding author: Camille Chesnel (iD https://orcid.org/0000-0002-8260-3678 Service de Neuro-Urologie, Hôpital Tenon, 4, rue de la Chine, 75020 Paris, France E-mail: camille.chesnel@aphp.fr / Tel: + 33-156016535 / Fax: + 33-156017481

* Members of the GRAPPPA.

† The members of the GRAPPPA are listed in the ACKNOWLEDGEMENTS section.

Submitted: December 8, 2017 / Accepted after revision: February 22, 2018 
clinical practice, we are going to manage more and more MS aging population, without strong knowledge on the specificity of aging with MS [2,3]. On the other side, micturition disorders are frequent in MS, approximately $78 \%$ of all MS patients will develop lower urinary tract symptoms (LUTS) during the disease [4]. Clinical and urodynamic characteristics of urinary dysfunction in MS are well described : urgency, frequency, urgency urinary incontinence are predominant with an estimated prevalence of $37 \%-99 \%$ whereas obstructive disorders are reported in $34 \%-79 \%$ of patients, leading to chronic urinary retention in $25 \%$ of patients [5]. Detrusor overactivity (DO) is the major bladder dysfunction with a prevalence of 65\% (34\%$99 \%$ ), however $25 \%$ of MS patients have detrusor underactivity, $35 \%(5 \%-83 \%)$ have a detrusor sphincter dyssynergia and 1to $34 \%$ have a normal cystometry $[5,6]$.

Otherwise, aging can determine numerous and various bladder dysfunctions [7-10]. Thus, urinary incontinence (urgency and stress urinary incontinence [SUI]) is more frequent in elderly and voiding dysfunction secondary to obstructive lesions in male (benign prostatic hypertrophy) or female (prolapse) can be observed in this population [7-10].

If MS and aging could determine separately urinary disorders, it could be interesting to evaluate in elderly MS if aging modify the typology of clinical features and therapeutic options.

Yet, some studies have demonstrated that age is not an influencing factor on clinical or urodynamic profile but these studies concerned a young population (age range, 35.9-48 years) [1114].

Thus, clinical and urodynamic profile of LUTS in geriatric population of MS remains unknown. Because of the consequences of LUTS on upper urinary tract, quality of life, mood, social relationship, risk of falling and the prevalence of osteoporosis, falls, comorbidities and gait disturbance in geriatric population of MS, characterization of urinary disorders is important to get an optimum care $[2,3,15,16]$.

The aim of the present study is to compare the clinical and urodynamic characteristics of urinary disorders in a geriatric population with a nongeriatric population of MS patients.

\section{MATERIALS AND METHODS}

This study was conducted retrospectively based on the first clinical and urodynamic evaluation in one day hospitalization in Neuro-urology Department of a University Hospital between
2010 and 2016. For each patient with MS aged 65 and older, 2 patients with MS aged less than 65 years old were matched in sex, form of MS, and Expended Disability Status Scale (EDSS).

Demographic data (body mass index and duration of the MS), urinary symptoms using the Urinary Symptom Profile (USP) [17] history of symptomatic urinary tract infection, bladder management (intermittent catheterization, indwelling urinary catheter, or micturition), use of diapers or condom catheter, urinary treatment, quality of life (Qualiveen) $[18,19]$ and repercussion of LUTS on daily life activities and psychological state using a visual analogue scale (VAS) were collected. The following parameters were analyzed: detrusor activity, maximum urethral closure pressure (MUCP), detrusor compliance, and cystometric capacity.

Conventional cystometries was assessed in accordance with International Continence Society (ICS) recommendations [2022].

Statistical analysis was carried out using R 3.2.3 software (R Foundation for Statistical Computing, Vienna, Austria, http:// www.R-project.org) and R studio version 1.0.136. Differences between the 2 populations of age (elderly or not) were evaluated using Student test for quantitative variables and chi-square or Fischer exact tests for categorical variables.

This study was approved by a local ethics committee (Comité de Protection des Personnes Ile de France II: 00001072). Since it was retrospective and no formalized informed consent was necessary according to the ethics committee, a letter was sent to the patients informing them that their data would be used, unless they contacted the investigators to express their disapproval.

\section{RESULTS}

In the elderly population of patients with MS, 24 patients were included and matched with 48 patients MS aged 65 or older. The mean age was 69.8 years old (standard deviation [SD], \pm 3.2 ) in the elderly population and 49.4 years old (SD, 9.3) in the less than 65 years old population. The mean EDSS was 6.4 (SD, \pm 1.2 ). All the subjects had both spinal cord and brain localization of MS plaques. Duration of MS was significantly longer in the elderly population than in the less than 65 years old population (20 years [SD, \pm 13.3 ] vs. 13.4 years [SD, \pm 9.4$], \mathrm{P}=0.04$ ).

In the male population, 5 patients aged $\geq 65$ years were matched with 10 patients ages $<65$ years. The MUCP was lower in the elderly population than in the nongeriatric population 
Table 1. Comparison of demographic, clinical, and urodynamic characteristics of lower urinary tract symptoms in the male subgroup

\begin{tabular}{|c|c|c|c|c|c|c|}
\hline \multirow{2}{*}{ Variable } & \multicolumn{2}{|c|}{ Population $\geq 65$ years old } & \multicolumn{2}{|c|}{ Population $<65$ years old } & \multirow{2}{*}{ Total No. } & \multirow{2}{*}{$\mathrm{P}$-value } \\
\hline & Value & No. & Value & No. & & \\
\hline Age (yr) & $68.6 \pm 3.2$ & 5 & $49.4 \pm 9.3$ & 10 & 15 & $<0.001$ \\
\hline EDSS & $6.3 \pm 1.4$ & 5 & $6.3 \pm 1.3$ & 10 & 15 & 1.00 \\
\hline $\begin{array}{l}\text { MS form }{ }^{\text {a) }} \\
\text { Progressive } \\
\text { RR }\end{array}$ & $\begin{array}{l}4(80) \\
1(20)\end{array}$ & 5 & $\begin{array}{l}8(80) \\
2(20)\end{array}$ & 10 & 15 & 1.00 \\
\hline MS duration & $13.2 \pm 7.8$ & 5 & $13.8 \pm 12.3$ & 10 & 15 & 0.91 \\
\hline Body mass index $\left(\mathrm{kg} / \mathrm{m}^{2}\right)$ & $26.7 \pm 6.3$ & 5 & $24.0 \pm 2.3$ & 10 & 15 & 0.41 \\
\hline Qualiveen total & $2.0 \pm 1.0$ & 4 & $1.6 \pm 1.3$ & 9 & 13 & 0.60 \\
\hline USP SUI & $0.6 \pm 1.3$ & 5 & $1.1 \pm 3.0$ & 9 & 14 & 0.67 \\
\hline USP OAB & $9.0 \pm 2.8$ & 5 & $7.7 \pm 4.9$ & 9 & 14 & 0.53 \\
\hline USP LS & $3.0 \pm 1.9$ & 5 & $2.7 \pm 2.9$ & 9 & 14 & 0.80 \\
\hline VAS DLA & $60.0 \pm 14.1$ & 4 & $40.0 \pm 43.1$ & 9 & 13 & 0.26 \\
\hline VAS psy & $57.5 \pm 9.6$ & 4 & $36.7 \pm 48.0$ & 9 & 13 & 0.24 \\
\hline $\begin{array}{l}\text { Voiding mode }^{\mathrm{a})} \\
\text { Catheterization }\end{array}$ & $0(0)$ & 5 & $1(10)$ & 10 & 15 & 0.46 \\
\hline $\begin{array}{l}\text { Symptomatic urinary tract infection } \\
\text { Yes }\end{array}$ & $3(60)$ & 5 & $2(20)$ & 10 & 15 & 0.25 \\
\hline $\begin{array}{l}\text { Condom catheter }{ }^{\mathrm{a})} \\
\text { Yes }\end{array}$ & $0(0)$ & 5 & $4(40)$ & 10 & 15 & 0.23 \\
\hline $\begin{array}{l}\text { Diapers } \\
\text { Yes }\end{array}$ & $1(50)$ & 2 & $2(20)$ & 10 & 12 & 0.46 \\
\hline $\begin{array}{l}\text { Urinary treatment }{ }^{\mathrm{a})} \\
\text { None } \\
\text { Ach } \\
\text { Ach and } \alpha- \\
\alpha- \\
\alpha \text { - and ISBT }\end{array}$ & $\begin{array}{l}3(60) \\
0(0) \\
1(20) \\
0(0) \\
1(20)\end{array}$ & 5 & $\begin{array}{l}4(40) \\
2(20) \\
1(10) \\
2(20) \\
1(10)\end{array}$ & 10 & 15 & 0.78 \\
\hline $\begin{array}{l}\text { Detrusor overactivity } \\
\text { Yes }\end{array}$ & $4(100)$ & 4 & $6(60)$ & 10 & 14 & 0.25 \\
\hline MUCP & $49.3 \pm 30.0$ & 3 & $136.0 \pm 83.4$ & 10 & 13 & 0.02 \\
\hline $\begin{array}{l}\text { Detrusor compliance }^{\text {a) }} \\
\text { Impaired }\end{array}$ & $1(25)$ & 4 & $0(0)$ & 10 & 14 & 0.29 \\
\hline Cystomanometric capacity & $340.0 \pm 71.2$ & 4 & $372.0 \pm 114.3$ & 10 & 14 & 0.54 \\
\hline
\end{tabular}

Values are presented as mean \pm standard deviation or number (\%).

EDSS, Expended Disability Status Scale; MS, multiple sclerosis; RR, relapsing-remitting; USP, urinary symptoms profile; SUI, stress urinary incontinence; OAB, overactive bladder; LS, low stream; VAS DLA, visual analogue scale for impact on daily life activities; VAS psy, visual analogue scale for impact on psychological state; Ach, anticholinergic drug; $\alpha$-, $\alpha$-adrenergic blocking drug; ISBT, intrasphincter botulinic toxin; MUCP, maximum urethral closure pressure.

${ }^{\text {a) }}$ Fischer exact test.

(49.3 $\pm 30.0 \mathrm{~cm} \mathrm{H} \mathrm{H}_{2} \mathrm{O}$ vs. $\left.136.0 \pm 83.4 \mathrm{~cm} \mathrm{H}_{2} \mathrm{O}, \mathrm{P}=0.02\right)$ without difference in SUI (USP SUI: $0.6 \pm 1.3$ vs. $1.1 \pm 3.0, \mathrm{P}=0.67$ ). There was no statistical difference in any other clinical or urodynamic endpoints (Table 1).
In the female population, 19 patients aged $\geq 65$ years were matched with 38 patients ages $<65$ years. Voiding symptoms was more described in the nongeriatric population (USP low stream: $3.4 \pm 3.5$ vs. $1.7 \pm 2.4, \mathrm{P}=0.04)$, geriatric population had 
Table 2. Comparison of demographic, clinical and urodynamic characteristics of lower urinary tract symptoms in the female subgroup

\begin{tabular}{|c|c|c|c|c|c|c|}
\hline \multirow{2}{*}{ Variable } & \multicolumn{2}{|c|}{ Population $\geq 65$ years old } & \multicolumn{2}{|c|}{ Population < 65 years old } & \multirow{2}{*}{ Total No. } & \multirow{2}{*}{$\mathrm{P}$-value } \\
\hline & Value & No. & Value & No. & & \\
\hline Age (yr) & $70.1 \pm 3.3$ & 19 & $49.7 \pm 9.4$ & 38 & 57 & $<0.001$ \\
\hline EDSS & $6.5 \pm 1.3$ & 19 & $6.5 \pm 1.2$ & 38 & 57 & 1.00 \\
\hline $\begin{array}{l}\text { MS form } \\
\text { Progressive } \\
\text { RR }\end{array}$ & $\begin{array}{r}14(74) \\
5(26)\end{array}$ & 19 & $\begin{array}{l}28(74) \\
10(26)\end{array}$ & 38 & 57 & 1.00 \\
\hline MS duration & $21.7 \pm 14.0$ & 19 & $13.3 \pm 8.7$ & 38 & 57 & 0.02 \\
\hline Body mass index $\left(\mathrm{kg} / \mathrm{m}^{2}\right)$ & $27.3 \pm 8.2$ & 17 & $24.0 \pm 5.1$ & 38 & 55 & 0.13 \\
\hline Qualiveen total & $1.4 \pm 1.0$ & 17 & $2.1 \pm 0.9$ & 35 & 52 & 0.02 \\
\hline USP SUI & $3.6 \pm 3.7$ & 18 & $2.9 \pm 3.3$ & 36 & 54 & 0.47 \\
\hline USP OAB & $10.7 \pm 4.7$ & 18 & $10.7 \pm 4.7$ & 36 & 54 & 0.97 \\
\hline USP LS & $1.7 \pm 2.4$ & 18 & $3.4 \pm 3.5$ & 36 & 54 & 0.04 \\
\hline VAS DLA & $38.2 \pm 30.1$ & 17 & $56.7 \pm 29.5$ & 36 & 53 & 0.04 \\
\hline VAS psy & $30.0 \pm 31.2$ & 17 & $57.4 \pm 29.4$ & 35 & 52 & 0.01 \\
\hline $\begin{array}{l}\text { Voiding mode } \\
\text { Catheterization }\end{array}$ & $3(13)$ & 19 & $10(26)$ & 38 & 57 & 0.51 \\
\hline $\begin{array}{l}\text { Symptomatic urinary tract infection } \\
\text { Yes }\end{array}$ & $10(53)$ & 19 & $20(53)$ & 38 & 57 & 1.00 \\
\hline $\begin{array}{l}\text { Diapers }^{\text {a) }} \\
\text { Yes }\end{array}$ & $13(87)$ & 15 & $28(74)$ & 38 & 53 & 0.47 \\
\hline $\begin{array}{l}\text { Urinary treatment }{ }^{\mathrm{a})} \\
\text { None } \\
\text { Ach } \\
\text { Ach and } \alpha- \\
\alpha- \\
\alpha-\text { and ISBT }\end{array}$ & $\begin{array}{c}15(79) \\
3(16) \\
0(0) \\
1(5) \\
0(0)\end{array}$ & 19 & $\begin{array}{c}20(53) \\
7(18) \\
10(26) \\
1(3) \\
0(0)\end{array}$ & 38 & 57 & 0.05 \\
\hline $\begin{array}{l}\text { Detrusor overactivity } \\
\text { Yes }\end{array}$ & $12(67)$ & 18 & $23(61)$ & 38 & 56 & 0.66 \\
\hline MUCP & $33.3 \pm 16.1$ & 18 & $63.0 \pm 25.4$ & 38 & 56 & $<0.001$ \\
\hline $\begin{array}{l}\text { Detrusor compliance }{ }^{\mathrm{a})} \\
\text { Impaired }\end{array}$ & $0(0)$ & 18 & $0(0)$ & 38 & 56 & 1.00 \\
\hline Cystomanometric capacity & $308.9 \pm 168.9$ & 18 & $340.8 \pm 165.2$ & 38 & 56 & 0.51 \\
\hline
\end{tabular}

Values are presented as mean \pm standard deviation or number (\%).

EDSS, Expended Disability Status Scale; MS, multiple sclerosis; RR, relapsing-remitting; USP, urinary symptoms profile; SUI, stress urinary incontinence; OAB, overactive bladder; LS, low stream; VAS DLA, visual analogue scale for impact on daily life activities; VAS psy, visual analogue scale for impact on psychological state; Ach, anticholinergic drug; $\alpha$-, $\alpha$-adrenergic blocking drug; ISBT, intrasphincter botulinic toxin; DO, detrusor overactivity; MUCP, maximum urethral closure pressure.

${ }^{a)}$ Fischer exact test.

less urinary treatment $(\mathrm{P}=0.05)$. The MUCP was lower in the elderly population than in the non-geriatric population $(33.3$ $\pm 16.1 \mathrm{~cm} \mathrm{H}_{2} \mathrm{O}$ vs. $\left.63.0 \pm 25.4 \mathrm{~cm} \mathrm{H}_{2} \mathrm{O}, \mathrm{P}<0.001\right)$ without difference in SUI (USP SUI: $3.6 \pm 3.7$ vs. $2.9 \pm 3.3, \mathrm{P}=0.47$ ) (Table 2). In the female elderly population, LUTS had less impact on psychological state (VAS for impact on psychological state: $30.0 \pm 31.2$ vs. $57.4 \pm 29.4, \mathrm{P}=0.01$ ), on daily life activities (VAS for impact on daily life activities: $38.2 \pm 30.1$ vs. $56.7 \pm 29.5$, $\mathrm{P}=0.04$ ) and on quality of life (Qualiveen: $1.4 \pm 1.0$ vs. $2.1 \pm 0.9$, $\mathrm{P}=0.02$ ) (Table 2). There was no statistical difference in any 
other clinical or urodynamic endpoints (Table 2).

\section{DISCUSSION}

With equal EDSS, sex, and MS form, geriatric population of male patients with MS has the same urinary disorders and the same impact on quality of life than a nongeriatric population of MS. In contrast, in the female population of patients with MS, voiding symptoms are less prevalent in the geriatric population than in the nongeriatric population, probably due to lower MUCP. LUTS impact less on psychological state, daily life activities, and quality of life in the geriatric female population than in the nongeriatric female population.

In the female population, Hannestad et al. [23] reported similar findings: the prevalence and the severity of incontinence increases with age while the rating of incontinence as a problem remains stable.

According to previous findings, we found that, MUCP is lower in the elderly population than in the less than 65 years old population $[23,24]$. There is no consensus in the ICS for the definition of intrinsic sphincter deficiency (ISD) [25]. The most commonly studied parameters to determine ISD are Valsalva leak point pressure (VLPP) and MUCP. Lower values of VLPP (typically $\left.<60 \mathrm{~cm} \mathrm{H}_{2} \mathrm{O}\right)$ or MUCP $\left(<20-30 \mathrm{~cm} \mathrm{H}_{2} \mathrm{O}\right)$ are commonly used as an indicator of ISD [25]. Without consensual definition of ISD, only value of MUCP was presented in this study. Prevalence of SUI was not different between the 2 populations. These results are not consistent with those observed in general population. Indeed, in general population, SUI increases with aging, and MUCP decreases with age $[23,24]$. In our geriatric population, stress situation was uncommon because of disability, lack of mobility, and age that could explain the absence of SUI in daily life. Furthermore, the similarity of SUI in the 2 populations could be explained by the detrusor sphincter dyssynergia present in suprasacral damage in MS. This detrusor sphincter dyssynergia could also explain the voiding symptoms in the young female group.

\section{Interest of the study topic}

The urinary incontinence in the elderly is a major topic: during the 6th International Consultation on Incontinence held in Tokyo in September 2016, the ICS recommended to focus on LUTS in the frail elderly [26]. The Consultation has defined "frail older persons" as those over the age of 65 with a clinical presentation or phenotype combining impaired physical activi- ty, mobility, balance, muscle strength, motor processing, cognition, nutrition, and endurance (including feelings of fatigue and exhaustion) [26]. MS constitute an additional frailty factor in the elderly population with LUTS. The knowledge of the LUTS typology in this frail elderly population is necessary to an optimum management of the patients.

\section{Limitations of the study}

The principal limitation of the present study is its retrospective design; this may generate a selection bias inducing a lack of power. In order to limit this bias, all patients aged 65 or older who underwent a specific one day hospitalization for MS were included. Moreover, the matching of the patients had been randomized. Another limitation of the study is the absence of nonMS control group. We assumed that in the LUTS of old MS patient, one part of these LUTS is related to MS and one other to aging. In order to evaluate the effect of aging on LUTS in a MS population we choose to compare a geriatric population with a nongeriatric population of MS patients. Despite the small number of patients, which is a limit of our study, it is the only cohort which studies LUTS in a geriatric population of MS.

In conclusion, geriatric population of male patient with MS has the same clinical and urodynamic characteristics as nongeriatric population with control EDSS, and form of MS. With few differences of urinary symptoms and urodynamic parameters, the impact of the LUTS is less important in the geriatric female population of MS than in the nongeriatric female patients with MS. Conversely, no change concerning overactive bladder/ overactive detrusor was observed while it could be thinkable that age and MS, by means of potentiation of pathophysiological factors, may increase rate and /or severity of overactive bladder in this specific population.

\section{ACKNOWLEDGEMENTS}

The authors would like to thank all members of the GRAPPPA (Groupe de Recherche Appliquée à la Pelvi-Périnéologie de la Personne Agée) for their valuable help.

The members of GRAPPPA (Clinical research Group of perineal dysfunctions in older adults): Gerard Amarenco, Xavier Deffieux, Brigitte Fatton, Xavier Game, Rebecca Haddad, Claire Hentzen, Claude Jeandel, Jacques Kerdraon, Pierre Mares, Matthieu Mezzadri, Anne Claire Petit, Benoit Peyronnet, Gilberte Robain, Jean Marc Vetel. 


\section{AUTHOR CONTRIBUTION STATEMENT}

- Full access to all the data in the study and takes responsibility for the integrity of the data and the accuracy of the data analysis: C. Chesnel, A. Charlanes, C. Hentzen, N. Turmel, F. Le Breton, S. Sheikh Ismael, G. Amarenco

-Study concept and design: C. Chesnel, A. Charlanes, C. Hentzen, N. Turmel, F. Le Breton, S. Sheikh Ismael, G. Amarenco

- Acquisition of data: C. Chesnel

- Analysis and interpretation of data: C. Chesnel, G. Amarenco

- Drafting of the manuscript: $C$. Chesnel

- Critical revision of the manuscript for important intellectual content: C. Chesnel, A. Charlanes, C. Hentzen, N. Turmel, F. Le Breton, S. Sheikh Ismael, G. Amarenco

- Statistical analysis: C. Chesnel, A Charlanes

-Study supervision: C. Chesnel, A. Charlanes, C. Hentzen, N. Turmel, F. Le Breton, S. Sheikh Ismael, G. Amarenco

\section{REFERENCES}

1. Leray E, Vukusic S, Debouverie M, Clanet M, Brochet B, de Sèze J, et al. Excess mortality in patients with multiple sclerosis starts at 20 years from clinical onset: data from a large-scale French observational study. PLoS One 2015;10:e0132033.

2. Buhse M. The elderly person with multiple sclerosis: clinical implications for the increasing life-span. J Neurosci Nurs 2015;47:333-9.

3. Stern M. Aging with multiple sclerosis. Phys Med Rehabil Clin N Am 2005;16:219-34.

4. Wiedemann A, Kaeder M, Greulich W, Lax H, Priebel J, KirschnerHermanns R, et al. Which clinical risk factors determine a pathological urodynamic evaluation in patients with multiple sclerosis? an analysis of 100 prospective cases. World J Urol 2013;31:229-33.

5. Wang T, Huang W, Zhang Y. Clinical characteristics and urodynamic analysis of urinary dysfunction in multiple sclerosis. Chin Med J (Engl) 2016;129:645-50.

6. Ruffion A, Castro-Diaz D, Patel H, Khalaf K, Onyenwenyi A, Globe D, et al. Systematic review of the epidemiology of urinary incontinence and detrusor overactivity among patients with neurogenic overactive bladder. Neuroepidemiology 2013;41:146-55.

7. DuBeau CE, Kuchel GA, Johnson T 2nd, Palmer MH, Wagg A; Fourth International Consultation on Incontinence. Incontinence in the frail elderly: report from the 4th International Consultation on Incontinence. Neurourol Urodyn 2010;29:165-78.

8. Jung HB, Kim HJ, Cho ST. A current perspective on geriatric lower urinary tract dysfunction. Korean J Urol 2015;56:266-75.
9. Wagg A, Gibson W, Ostaszkiewicz J, Johnson T 3rd, Markland A, Palmer MH, et al. Urinary incontinence in frail elderly persons: report from the 5th International Consultation on Incontinence. Neurourol Urodyn 2015;34:398-406.

10. McGrother CW, Donaldson MM, Hayward T, Matthews R, Dallosso $\mathrm{HM}$, Hyde $\mathrm{C}$, et al. Urinary storage symptoms and comorbidities: a prospective population cohort study in middle-aged and older women. Age Ageing 2006;35:16-24.

11. Sliwa JA, Bell HK, Mason KD, Gore RM, Nanninga J, Cohen B. Upper urinary tract abnormalities in multiple sclerosis patients with urinary symptoms. Arch Phys Med Rehabil 1996;77:247-51.

12. Koldewijn EL, Hommes OR, Lemmens WA, Debruyne FM, van Kerrebroeck PE. Relationship between lower urinary tract abnormalities and disease-related parameters in multiple sclerosis. J Urol 1995;154:169-73.

13. Giannantoni A, Scivoletto G, Di Stasi SM, Grasso MG, Vespasiani G, Castellano V. Urological dysfunctions and upper urinary tract involvement in multiple sclerosis patients. Neurourol Urodyn 1998; 17:89-98.

14. Mayo ME, Chetner MP. Lower urinary tract dysfunction in multiple sclerosis. Urology 1992;39:67-70.

15. Sand PK, Sand RI. The diagnosis and management of lower urinary tract symptoms in multiple sclerosis patients. Dis Mon 2013; 59:261-8.

16. Dong G, Zhang N, Wu Z, Liu Y, Wang L. Multiple sclerosis increases fracture risk: a meta-analysis. Biomed Res Int 2015;2015: 650138

17. Haab F, Richard F, Amarenco G, Coloby P, Arnould B, Benmedjahed $\mathrm{K}$, et al. Comprehensive evaluation of bladder and urethral dysfunction symptoms: development and psychometric validation of the Urinary Symptom Profile (USP) questionnaire. Urology 2008; $71: 646-56$.

18. Costa P, Perrouin-Verbe B, Colvez A, Didier J, Marquis P, Marrel A, et al. Quality of life in spinal cord injury patients with urinary difficulties. Development and validation of qualiveen. Eur Urol 2001; 39:107-13.

19. Bonniaud V, Bryant D, Parratte B, Gallien P, Guyatt G. Qualiveen: a urinary disorder-specific instrument for use in clinical trials in multiple sclerosis. Arch Phys Med Rehabil 2006;87:1661-3.

20. Abrams P, Cardozo L, Fall M, Griffiths D, Rosier P, Ulmsten U, et al. The standardisation of terminology of lower urinary tract function: report from the Standardisation Sub-committee of the International Continence Society. Neurourol Urodyn 2002;21:167-78.

21. Schäfer W, Abrams P, Liao L, Mattiasson A, Pesce F, Spangberg A, et al. Good urodynamic practices: uroflowmetry, filling cystometry, 
and pressure-flow studies. Neurourol Urodyn 2002;21:261-74.

22. Lose G, Griffiths D, Hosker G, Kulseng-Hanssen S, Perucchini D, Schäfer W, et al. Standardisation of urethral pressure measurement: report from the Standardisation Sub-Committee of the International Continence Society. Neurourol Urodyn 2002;21:258-60.

23. Hannestad YS, Rortveit G, Sandvik H, Hunskaar S; Norwegian EPINCONT study. Epidemiology of Incontinence in the County of Nord-Trøndelag. A community-based epidemiological survey of female urinary incontinence: the Norwegian EPINCONT study. Epidemiology of Incontinence in the County of Nord-Trøndelag. J Clin Epidemiol 2000;53:1150-7.
24. Pfisterer MH, Griffiths DJ, Schaefer W, Resnick NM. The effect of age on lower urinary tract function: a study in women. J Am Geriatr Soc 2006;54:405-12.

25. Osman NI, Li Marzi V, Cornu JN, Drake MJ. Evaluation and classification of stress urinary incontinence: current concepts and future directions. Eur Urol Focus 2016;2:238-44.

26. Wagg A, Chen L, Johnson T, Kirschner-Hermanns R, Kuchel G, Markland A, et al. Incontinence in frail older persons. In: Abrams $\mathrm{P}$, Cardozo L, Wagg A, Wein A, editors. Incontinence. 6th ed. Tokyo: International Consultation on Incontinence; 2016. p. 1309-442. 